http://dx.doi.org/10.18675/1981-8106.vol26.n51.p97-111

\title{
Formação continuada e prática pedagógica: $O$ que pensam as professoras que atuam na pré-escola
}

Continuing education and pedagogical practice: What do teachers who work in preschool think about it.

Formación continua y práctica pedagógica: qué piensan las profesoras que actúan en la preescuela.

\author{
Rosane Penha Mendes - Mestre em Educação' \\ Maria Izete de Oliveira - Doutora em Educação" \\ Rinalda Bezerra Carlos - Doutora em Educação"II \\ ' Secretaria Municipal de Educação de Cáceres, Mato Grosso - Brasil. E-mail: \\ rosane.pmendes@gmail.com \\ "Universidade do Estado de Mato Grosso (UNEMAT), Mato Grosso - Brasil. E-mail: \\ mariaizete@gmail.com \\ II' Universidade do Estado de Mato Grosso(UNEMAT), Mato Grosso - Brasil. E-mail: \\ rinalda@unemat.br
}

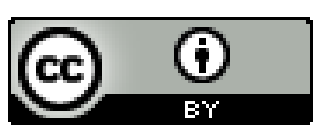

Educação: teoria e prática, Rio Claro, SP, Brasil - eISSN: 1981-8106

Está licenciada sob Licença Creative Common

\section{Resumo}

Este artigo apresenta resultados de uma pesquisa que teve como objetivo analisar se a formação continuada, em três instituições de Educação Infantil, está repercutindo na prática pedagógica das professoras. A pesquisa teve como técnicas de coleta de dados a observação da prática docente, o questionário, a entrevista com as coordenadoras pedagógicas e a análise dos projetos de formação continuada. Para este artigo, optamos por apresentar os dados obtidos no questionário respondido por sete professoras, cujo instrumento teve por finalidade conhecer o perfil das professoras que atuam na pré-escola, verificar o que pensam sobre sua prática na Educação Infantil e compreender as suas concepções sobre a formação continuada 
oferecida nas instituições pesquisadas. Nossos resultados apontaram que a formação continuada trouxe contribuições para melhoria da prática docente, porém, revelou aspectos a serem revistos pela coordenação pedagógica e corpo docente para que a formação possa atender às necessidades do contexto educativo.

Palavras-chave: formação continuada, prática pedagógica, pré-escola.

\begin{abstract}
This paper presents the results of a survey that aimed to examine whether continuing education in three educational institutions for children, is reverberating in the pedagogical practice of the teachers. The research had as data-collection techniques observation of teaching practice, questionnaire, interview with the pedagogical coordinators and the analysis of continuing education projects. In this paper, we present the data obtained from the questionnaire answered by seven teachers, which it was intended to meet the profile of the teachers working in the preschool, check what they think about their practice in early childhood education and to understand their conceptions of the continuing education offered by institutions surveyed. Our results showed that the continuing education brought contributions to the improvement of pedagogical practice, however, revealed aspects to be reviewed by the pedagogical faculty and coordination so that the training can meet the needs of the educational context.
\end{abstract}

Keywords: Continuing Education, Pedagogical Practice, Kindergarten.

\title{
Resumen
}

Este artículo presenta los resultados de una investigación que tuvo como objetivo analizar si la formación continua, en tres instituciones de Educación Infantil, está repercutiendo en la práctica pedagógica de las profesoras. La investigación tuvo como técnicas de recolección de datos la observación de la práctica docente, el cuestionario, la entrevista con las coordinadoras pedagógicas y el análisis de los proyectos de formación continua. Para este artículo, optamos por presentar los datos obtenidos en el cuestionario respondido por siete profesoras, cuyo instrumento tuvo como finalidad conocer el perfil de las profesoras que actúan en la preescuela, verificar qué piensan sobre su práctica en la Educación Infantil y comprender sus concepciones sobre la formación continua ofrecida en las instituciones estudiadas. Nuestros resultados apuntaron que la formación continua trajo contribuciones para la mejoría de la práctica docente, aunque reveló aspectos a ser revistos por la coordinación pedagógica y cuerpo docente para que la formación pueda atender las necesidades del contexto educativo.

Palabras clave: formación continua, práctica pedagógica, preescuela. 
A história da infância e da Educação Infantil no Brasil é marcada por reivindicações e debates em nível nacional em torno do atendimento à criança levando, com o passar do tempo, à elaboração de inúmeros documentos educacionais que culminaram em políticas públicas para melhoria da qualidade da Educação Infantil e do acesso a esta etapa da educação básica. Neste processo, estudos contemporâneos realizados por Gatti e Barreto (2009), Imbernón (2010) e Oliveira (2011) asseguram que nos últimos anos ocorreu grande interesse por parte das esferas governamentais, de estudiosos e pesquisadores sobre a Formação Continuada de professores da educação. Este tema tem construído uma trajetória marcada por debates, reflexões e produções significativas, em busca de uma compreensão mais elaborada acerca da concepção de educação que atenda as necessidades do ensino-aprendizagem oferecido nos diversos contextos educativos, dentre eles a educação básica.

Gatti e Barreto (2009) esclarecem que o crescente interesse de pesquisadores pela formação continuada tem como propósito a atualização e o aprofundamento de conhecimentos como requisito natural do trabalho em face do avanço do conhecimento, da mudança no campo das tecnologias, dos rearranjos nos processos produtivos e suas repercussões sociais. Em busca da qualidade do ensino, os investimentos realizados exigem cada vez mais o aperfeiçoamento da prática docente. Assim, a formação continuada complementa os conhecimentos adquiridos na formação inicial, tendo o papel de ressignificar a prática docente.

\section{A importância da formação continuada para mudanças na prática docente}

De acordo com estudos e pesquisas realizadas na área da educação foi possível perceber que os últimos trinta anos foram tempos marcantes para a educação e para a formação de professores, pois avanços ocorreram nas políticas de formação, mas, na realidade, com pouco efeito. Segundo Gatti e Barreto (2009), a formação de professores no país sofre os impactos do crescimento recente e rápido das redes públicas e privadas, haja vista que os últimos trinta anos foram marcados pelas reformas educacionais que culminaram em avanços nas políticas de formação inicial e continuada. Neste sentido, o percurso da formação, desde os anos de 1970, busca por alternativas e mudanças da instituição educacional que se encontrava presa a posições autoritárias, uniformizadoras, seletivas e classistas.

Imbernón (2010) enfatiza que na década de 1970, tempos que se aplicava a ideia 'forme-se onde puder e como puder', a formação continuada vivenciou um modelo individual em que cada um buscava para si a vida formativa, primando pela formação inicial, que apresentava ser boa ou ruim, segundo a época e o território.

Com os crescentes problemas nos cursos de formação inicial de professores, a iniciativa de formação continuada como aperfeiçoamento profissional foi se deslocando para 
uma concepção de formação compensatória (GATTI; BARRETO, 2009). Ainda de acordo com as autoras, a baixa qualidade da formação de professores foi um dos motivos da formação continuada não alcançar resultados satisfatórios para o ensino na década de 1980 . Dessa forma, intensificaram-se os debates sobre formação de professores, representando um desafio para as políticas públicas no Brasil.

Assim sendo, a baixa qualidade da formação de professores foi um dos motivos de a formação continuada não alcançar resultados satisfatórios para o ensino na década de 1980 (GATTI; BARRETO, 2009).

Outro fator que tem contribuído para que a formação continuada não alcance resultados significativos é a ausência da participação dos professores como categoria profissional na definição das políticas de formação docente e na formulação de projetos que têm a instituição educativa como o lugar central do seu fazer pedagógico. Gatti e Barreto (2009) salientam que, nas condições dadas, os professores não se envolvem, não se apropriam dos princípios elencados pelas reformas e, por fim, não se sentem motivados a mudar a forma como vêm desenvolvendo a sua prática educativa.

Oliveira (2011, p. 9) corrobora com esta colocação ao ressaltar que pesquisas recentes na área apontam que os professores são profissionais essenciais nos processos de mudança das sociedades. Nessa direção, se os professores "forem deixados à margem, as decisões pedagógicas e curriculares [...], por mais interessantes que possam parecer, não se efetivam, não geram efeitos", pois, o envolvimento dos profissionais nas decisões e elaboração de políticas públicas para formação de professores é fundamental para melhoria da qualidade na educação.

Nesse sentido, é preciso investir na formação e no desenvolvimento profissional dos professores, pois o envolvimento dos profissionais nas ações educativas, certamente, refletirá em mudança na sociedade, tornando-a mais justa e igualitária, tal como, conhecedora de seus direitos e deveres para com a educação deste país.

Para Oliveira (2011, p. 30-31), a demanda por qualificação profissional tem crescido nos últimos anos na educação básica, e, em particular, na Educação Infantil. Assim entendemos que é preciso investir na formação e no desenvolvimento profissional o que, a nosso ver, está relacionado com o desenvolvimento da capacidade de avaliar situações e comportamentos. Para tanto, a formação continuada deve, necessariamente, ser contemplada no Projeto Pedagógico que, por sua vez, demanda um projeto de formação que considere as necessidades específicas de cada etapa da educação.

Sendo assim, a formação continuada deve ser voltada para os estudos da realidade educacional, dando ênfase aos problemas concretos do cotidiano escolar, visando à construção de novas alternativas de ação pedagógica. Para que haja construção de alternativas inovadoras para ação docente, há necessidade de articulação entre as instituições educacionais, as 
universidades e o poder público, a fim de encontrar meios para tornar mais atrativa e interessante a formação continuada desenvolvida nas instituições educativas.

Para além dessas proposições, no que se refere à formação do professor da Educação Infantil, Oliveira (2011, p. 24-25) assevera:

Tal formação deve considerar que a diversidade está presente nas creches e pré-escolas não só em relação às faixas etárias das crianças e ao número de horas semanais em que ocorre o atendimento a elas, mas também em relação aos objetivos defendidos e às programações de atividades efetivadas em seu cotidiano.

Refletir sobre o que pretendemos que a criança na faixa etária da Educação Infantil aprenda, está estritamente ligado à formação que se pretende para o professor. Ou seja, o que se pretende para as crianças e a formação docente são temas indissociáveis, posto que acreditamos na relação existente entre a formação continuada e a prática pedagógica desenvolvida pelo professor.

Nessa compreensão, a formação inicial e continuada assume grande importância para que se efetive uma prática pedagógica que atenda às necessidades da criança. Conforme explicita Kramer (2005), a Educação Infantil precisa de profissionais preparados para atuar com essa faixa etária e que esteja em constante atualização pedagógica para que possa garantir às crianças uma educação que contemple suas especificidades.

Em suma, pensar em formação continuada para professores que atuam na Educação Infantil é pensar em um atendimento que respeite as especificidades de cada faixa etária, é pensar na qualidade da educação, é pensar em práticas pedagógicas que contemplem as características próprias da criança e de seu desenvolvimento, por fim, é pensar em um profissional que desempenhe bem a sua função junto à criança.

Por acreditarmos na formação continuada como ação imprescindível às mudanças na prática pedagógica de profissionais que atuam na Educação Infantil é que realizamos a pesquisa apresentada a seguir.

\section{Contextualizando a pesquisa}

Por ser este estudo fruto de nossas inquietações acerca da qualidade do atendimento oferecido às crianças que frequentam a pré-escola, realizamos a pesquisa em 03 (três) instituições municipais de Educação Infantil localizadas na cidade de Cáceres-MT. Assim, utilizamos dois critérios para seleção dos professores: os efetivos e os que atuam com a préescola, totalizando 07 (sete) professoras.

Vale esclarecer que na pesquisa que deu origem a este artigo, buscamos verificar se os resultados das ações pedagógicas são reflexos dos estudos realizados nos cursos de formação continuada. Para tanto, nos amparamos em quatro instrumentos: observação, questionário, entrevista semiestruturada e análise dos projetos de formação continuada das instituições 
pesquisadas. Entretanto, para o presente artigo, apresentamos apenas os resultados obtidos por meio do questionário que, na visão de Gil (2009), pode ser definido como uma técnica de investigação com propósito de obter informações sobre conhecimentos, crenças, sentimentos, valores, interesses, expectativas, aspirações, comportamentos, etc.

Nesse viés, este instrumento teve por finalidade conhecer o perfil das professoras que atuam na pré-escola, verificar o que pensam sobre sua prática na Educação Infantil e compreender as suas concepções sobre a formação continuada oferecida nas três instituições pesquisadas.

\section{Análise do Questionário}

Com interesse em conhecer se a formação continuada está contribuindo com a prática pedagógica das professoras, foi aplicado um questionário com a participação de professoras que atuam na Educação Infantil.

No questionário foram contempladas 13 (treze) questões, sendo 10 (dez) abertas e 3 (três) questões fechadas. A aplicação do questionário ocorreu após conversa com cada professora a fim de esclarecer a importância de sua participação neste trabalho. Cada participante da pesquisa respondeu ao questionário individualmente e em dias alternados, conforme disponibilidade dos sujeitos.

O questionário foi respondido por 07 (sete) professoras que atuam na pré-escola com crianças de 4 e 5 anos de idade e, a partir das informações obtidas, deu-se início às análises.

\section{Perfil das professoras}

É interessante ressaltar que dos sete sujeitos pesquisados, apenas um é do sexo masculino, o que vai ao encontro do que preconiza Gatti e Barreto (2009) ao constatarem, em sua pesquisa, a predominância do sexo feminino na educação básica, em particular na Educação Infantil, por esta ainda carregar uma conotação de cunho materno. Fato este que nos levou a tratar os nossos sujeitos no gênero feminino.

Quanto à "formação acadêmica das professoras" constatamos que todas são graduadas em pedagogia e duas possuem mais de uma graduação, sendo a segunda específica para a Educação Infantil. Seis professoras possuem especialização; destas, três em Educação Infantil. Analisando o nível de formação das professoras, podemos dizer que nas instituições de Educação Infantil pesquisada encontra-se um quadro de profissionais com formação que supera a exigência da LDBEN n 9394/1996, quando destaca que para atuar na Educação Infantil aceitar-se-á como formação mínima aquela oferecida em nível médio, modalidade Normal.

Buscamos saber sobre o "tempo de atuação das professoras na Educação Infantil" e os dados revelam que das sete professoras, seis possuem entre 5 a 12 anos de experiência com esta etapa da educação e uma atua há 2 anos. Isso significa que a maioria das professoras possui um tempo significativo de atuação que poderia contribuir para a melhoria de sua prática pedagógica. Esta inferência justifica-se pelo fato de acreditarmos que os anos de 
atuação contribuem para o profissional aperfeiçoar sua prática ao adquirir experiências e compartilhá-las com seus pares, numa perspectiva dialética de ação-reflexão-ação.

\section{O que dizem as professoras sobre práticas pedagógicas}

Antes de discutir a respeito do que pensam as professoras sobre a formação continuada, buscamos compreender o ponto de vista das professoras sobre o "sentimento de ser professora de Educação Infantil". Para tanto, organizamos as respostas por meio de indicadores formando categorias interpretativas para constatar o que mais se evidenciava nas respostas das professoras. Assim, suas falas foram classificadas em três categorias: 1) Sentese feliz com seu trabalho; 2) Compromisso com a profissão; e 3) Valorização da Educação Infantil.

Constatamos que a maioria das professoras sente-se satisfeita em atuar na Educação Infantil, sendo que apenas 01 (uma) respondeu estar insatisfeita em ser professora dessa faixa etária. O motivo apresentado por esta professora foi que algumas vezes se sente abandonada, pois faltam recursos para trabalhar de forma que possa contribuir para o desenvolvimento da aprendizagem das crianças. Ela argumenta, ainda, que faz seu planejamento, mas sempre tem que improvisar por falta de material e, assim, não consegue alcançar seus objetivos.

Nas justificativas sobre o porquê se sentem satisfeitas com a profissão, foi possível observar na categoria Sente-se feliz com seu trabalho, que as professoras estão entusiasmadas com a profissão e sentem vontade de aprender mais sobre o que fazem. $\mathrm{Na}$ categoria Compromisso com a profissão notamos o interesse das professoras em melhorar a prática pedagógica, demonstrando compreensão de que o trabalho docente exige reflexão sobre a prática para que as mudanças aconteçam. Estas respostas nos remetem ao pensamento de Kramer (2005, p. 216) ao enfatizar que são as ações de profissionais comprometidos, e em permanente formação, que possibilitarão que seja atingido o objetivo legal da Educação Infantil, ou seja, o desenvolvimento integral e integrado das crianças.

$\mathrm{Na}$ categoria Valorização da Educação Infantil, as professoras afirmam que mudanças estão acontecendo nesta etapa e que novas concepções desconstroem os pensamentos por muito tempo arraigados de que o profissional que atua na Educação Infantil só serve para cuidar de crianças. Nesse sentido, Barbosa (2010) salienta que a profissão da professora não se resume, como muitos acreditam, apenas à continuidade dos fazeres 'maternos', mas uma construção da profissionalização que exige, além de competência teórica, também metodológica e relacional. Para a autora, atuar na Educação Infantil exige que as profissionais estejam em constante construção de conhecimentos.

De acordo com o que constatamos nas respostas das professoras podemos inferir que elas estão construindo um novo olhar em relação às crianças pequenas, e isto pode ser resultado da formação continuada oferecida pelas instituições, bem como do nível de formação acadêmica que possuem. Mas é preciso outras pesquisas a fim de verificar se esta constatação será ratificada nos novos resultados. 


\section{O que pensam as professoras sobre a formação continuada}

Buscamos saber primeiramente "se as escolas em que as professoras atuam oferecem a formação continuada". Percebemos que as professoras são unânimes ao afirmar que nas instituições há o momento destinado para realização da formação. Para OliveiraFormosinho e Formosinho (2002, p. 8), este modelo de formação centrado na escola "implica uma aproximação diferente do papel do professor formando na sua formação". Assim, o fato das escolas pesquisadas oferecerem formação nos leva a crer que a equipe pedagógica tem dado atenção e importância necessária para que a formação continuada seja realizada no contexto educacional e isso parece apontar para novos olhares em busca de mudanças na prática pedagógica. Nesse viés, Imbernón (2010) afirma que uma nova forma de ver a educação e a formação dos professores passa necessariamente por uma compreensão sobre o que está ocorrendo diante das especificidades das áreas do currículo, das mudanças vertiginosas do contexto, dos avanços tecnológicos e da forma de organização nas instituições escolares. Esses são alguns fatores que implicam uma nova visão para a formação docente.

Ao procurarmos saber "se houve participação das professoras na elaboração do projeto de formação continuada da escola", uma respondeu não ter participado da elaboração por não ter sido comunicada em tempo, mas justificou que depois de alguns meses teve oportunidade de contribuir com sugestões para a formação. As outras seis professoras responderam ter participado da elaboração do projeto, o que nos leva a inferir que a escola trabalha de maneira integrada no que tange à formação continuada. Concluímos, portanto, que há interesse e respeito pelas professoras por parte daqueles que estão à frente da formação e do trabalho pedagógico nas instituições pesquisadas ao abrir espaço para que participem e opinem.

Entendemos que promover a participação dos profissionais na construção da proposta de formação na escola é uma atitude que conduz à melhoria do trabalho docente, pois é oportuno para levantamentos das reais necessidades da instituição, das temáticas a serem estudadas e debatidas entre os pares durante a formação. Neste sentido, Imbernón (2010, p. 43) afirma que "isso faz com que a formação esteja a serviço do projeto elaborado por um grupo. Quando se elabora um projeto, os professores podem escolher a teoria que lhes ajudará a colocá-lo em prática”.

Posteriormente, buscamos saber se "as professoras participam da formação continuada da escola" e, mais uma vez, todas foram unânimes em responder que participam. Esta participação maciça das professoras pesquisadas na formação contradiz, de forma positiva, a realidade constatada por Gatti e Barreto (2009) em sua pesquisa, ao identificar que as professoras, de modo geral, não se envolvem na formação. As autoras alertam sobre a importância da participação dos professores nos estudos oferecidos pela instituição visando o crescimento profissional, uma vez que a formação tem como objetivo contribuir para melhoria da prática docente.

Na sequência, foi indagado "se a formação continuada atende as expectativas das professoras". Constatamos que cinco responderam positivamente, sendo que duas não justificaram suas respostas. As que justificaram disseram que o momento da formação oportuniza o surgimento de temas que vêm ao encontro da necessidade de cada realidade educativa, contribuindo para aperfeiçoar sua prática pedagógica. Uma professora disse que "de certa forma sim" e o motivo pelo qual a formação continuada ainda não atende sua expectativa está relacionado a condições de infraestrutura da instituição. Ela afirma estar 
frustrada com as condições materiais e de infraestrutura que o ambiente educativo oferece. Esta professora respondeu que, em outros aspectos, a formação atende suas expectativas, ou seja, entendemos que em se tratando de questões pedagógico-metodológicas sua resposta foi positiva. Outra professora, aquela que não participou desde a elaboração da proposta, respondeu que inicialmente não estava satisfeita com a formação, mas justificou que houve reelaboração e isso oportunizou sua participação junto aos colegas na escolha das temáticas para a formação que veio a atender as suas expectativas. Percebemos que esta professora, anteriormente, também respondeu não ter participado da elaboração do projeto de formação continuada, mas justificou que depois de algum tempo teve oportunidade de expressar suas sugestões, contribuindo com a melhoria da proposta de formação. Podemos inferir que a maioria das professoras está satisfeita com a formação porque elas se envolvem participando do processo de construção do projeto de formação continuada contribuindo, desta forma, para que as leituras atendam a realidade do contexto em que estão inseridas.

Isso pode ser ratificado quando, em outra questão, procuramos identificar se "as temáticas trabalhadas na formação vêm ao encontro da realidade educacional da escola". Apenas uma professora respondeu que "às vezes" as temáticas discutidas na formação condizem com a realidade da escola, isto é, para ela nem sempre as discussões propostas atendem a realidade, porém as outras seis professoras afirmam que "as temáticas vêm ao encontro das suas necessidades". É certo que para as temáticas discutidas na formação atenderem à realidade da instituição é preciso ouvir os profissionais sobre suas concepções, suas sugestões, os desejos, os conflitos vividos no meio educacional e a partir daí definir as prioridades que irão fazer parte dos estudos nos encontros de formação.

Buscamos saber "se as teorias estudadas na formação são transpostas para a prática das professoras", seis responderam de forma afirmativa, sendo que a mesma professora que respondeu "às vezes" para a questão anterior (se a formação vem ao encontro de sua realidade), respondeu não utilizar na prática aquilo que é estudado na formação, justificando que nem tudo que é proposto ela consegue desenvolver e, novamente, menciona falta de material didático. Diante da justificativa desta professora, é possível inferir que a quantidade reduzida de materiais pedagógicos disponibilizados pelo sistema público para as instituições estudadas está dificultando o desenvolvimento do seu trabalho. Concordamos que a falta de materiais pedagógicos pode dificultar o desenvolvimento de algumas atividades, porém, isso não é fator principal para impossibilitar uma prática de qualidade. Entendemos que o brincar, o conto de história, a música, o faz de conta, são atividades fundamentais que devem fazer parte do cotidiano da Educação Infantil, e não demandam de grandes quantidades de materiais. No entanto, é preciso que a professora amplie seus conhecimentos teóricos sobre o desenvolvimento e aprendizagem da criança, bem como, reflita sobre sua prática pedagógica de forma a perceber as diferentes possibilidades existentes para realizar essas atividades.

Nesse sentido, Kramer (2005) esclarece que para ter qualidade na Educação Infantil é necessária a atuação de profissionais qualificados que façam as mediações entre as crianças e os recursos pedagógicos.

Não bastam os recursos sem a possibilidade de as crianças interagirem. $\mathrm{O}$ planejamento, a organização, a execução, o acompanhamento, a avaliação do trabalho e a atenção individual às crianças exigem profissionais de educação infantil com sensibilidade, formação inicial consistente e em constante 
atualização e reflexão sobre a sua prática. Isto é, faz-se urgente a formação de profissionais dinâmicos, afetivos, que gostem de brincar, conheçam as características das crianças, estudem e investiguem sobre seu desenvolvimento, capazes de sintonizar com as necessidades delas, ampliando sua curiosidade e leitura de mundo (KRAMER, 2005. p. 214215).

Para a autora, a qualidade no atendimento à criança, implica na inter-relação entre os recursos materiais e humanos. Ressalta ainda, a importância de uma formação que realmente prepare o professor para atuar com essas crianças, de forma que promova o seu desenvolvimento e aprendizagem.

Em outra questão "se a formação continuada tem contribuído com a prática pedagógica das professoras", tivemos por objetivo verificar se as respostas dadas na questão anterior se confirmariam. Percebemos que as sete professoras responderam afirmativamente, o que vai ao encontro das respostas obtidas anteriormente. Surpreendeu-nos o fato daquela professora que se mostrou insatisfeita com as temáticas estudadas agora assinalar que a formação contribui para sua prática. Chamou-nos a atenção ainda o fato de todas as professoras afirmarem que a formação contribui para a relação teoria/prática.

Neste sentido, é válido nos reportar à pesquisa realizada por Kramer (2005), que analisou a formação de profissionais da Educação Infantil, na qual as professoras revelam uma formação precária que expropria o professor de sua prática no sentido de "ausência de práxis, da teoria como reflexão sobre e para a prática, feita com o outro, como leitura de mundo, crítica e ativa, que reúne saber, fazer e falar" (KRAMER, 2005, p. 95-96).

Já as professoras por nós pesquisadas esclarecem que os temas discutidos na formação são relevantes e essenciais para direcionar sua prática pedagógica. Esta constatação nos leva a inferir que as professoras têm se conscientizado da importância da inter-relação teoria/prática, fortalecendo as tomadas de decisões. De acordo com Kramer (2005), as propostas de formação devem conter "garantias e condições para que a teoria e a prática fortaleçam os professores, para que a teoria não seja vista como soberana sobre a experiência, da mesma forma que a experiência não substitui a análise crítica, sendo, na verdade, mediada por ela" (apud BODNAR, 2011, p. 199). Assim, os conhecimentos teórico e prático são importantes para melhor compreensão do contexto educativo e das possíveis mudanças no fazer pedagógico. Ao analisar esta categoria constatamos que as professoras, ao considerarem que a teoria é fundamental para contribuir com a melhoria da prática pedagógica, sentem a necessidade de dar sugestões para que a formação seja um momento atrativo e interessante.

Parece-nos que os reflexos da formação continuada atingem as professoras, contribuindo para aperfeiçoar sua prática pedagógica. Isto é importante a partir do momento que essas profissionais percebem que precisam abdicar de determinadas práticas realizadas com crianças, visando à melhoria da ação docente. Acreditamos, então, que a Educação Infantil passa a adquirir um novo olhar por parte dessas professoras. Um olhar que busca 
contribuir de forma significativa para o desenvolvimento e aprendizagem da criança nessa faixa etária.

Desse modo, acreditamos que a formação continuada nas escolas pesquisadas, aos poucos, está refletindo na prática dos sujeitos envolvidos, pois as teorias estudadas têm feito com que as professoras busquem cada vez mais o aperfeiçoamento das ações propostas por elas na Educação Infantil. Neste sentido, nos reportamos a Imbernón (2010, p. 47) quando expressa sobre "o que e como" a formação poderia contribuir com os professores.

A formação continuada deveria apoiar, criar e potencializar uma reflexão real dos sujeitos sobre sua prática docente nas instituições educacionais e em outras instituições, de modo que lhes permitisse examinar suas teorias implícitas, seus esquemas de funcionamento, suas atitudes, etc., estabelecendo de forma firme um processo constante de autoavaliação do que se faz e por que se faz.

Para Imbernón, é preciso abandonar o conceito tradicional de que a formação continuada é a atualização científica, didática e psicopedagógica, que pode ser recebida mediante certificados de estudo. Para o autor, a formação deve possibilitar aos professores a análise e reflexão crítica sobre a prática, contribuir para a tomada de decisão racional, para a avaliação de processos educativos e para a reformulação de projetos que atendam a realidade onde estão inseridos.

Em outra questão, indagamos se "a carga horária designada à formação é suficiente para o entendimento e compreensão das temáticas trabalhadas". Contrariamente às outras questões, a maioria das professoras, cinco, respondeu "às vezes", o que significa que o tempo é insuficiente para a discussão de algumas temáticas. As outras duas professoras responderam que o tempo é suficiente. As professoras, ao justificarem que "às vezes" o tempo é insuficiente, afirmam que alguns temas, por serem muito importantes, necessitam de maior aprofundamento, mas o tempo exíguo não possibilita essa ação. Neste mesmo sentido, uma professora ressaltou que falta melhor compreensão das temáticas estudadas e sugeriu a colaboração de profissionais mais habilitados para indicar aportes teóricos e sanar dúvidas. Esse interesse das professoras pela teoria é extremamente significativo, pois ao buscarem conhecimento refletem sobre a prática, e isso pode culminar na qualidade do trabalho desenvolvido nas instituições.

Entretanto, não basta ter profissionais habilitados para conduzir determinadas temáticas, é importante a colaboração de todos para que se tenha uma formação que possa atender as expectativas dos professores, visando melhores resultados na prática pedagógica docente. Neste sentido, outra professora ressalta que é preciso que os professores focalizem mais as discussões nas elaborações de projetos, otimizando esse momento de formação e de construção coletiva.

Ao questionarmos "se as professoras participam de outras formações", cinco delas responderam que "não" e duas professoras, uma que atua também na rede privada e a outra na rede estadual, afirmaram que participam da formação dessas instituições. Percebemos, então, que a maioria das professoras só tem como opção de formação continuada aquela 
oferecida pela instituição de Educação Infantil na qual atua. Esta constatação evidencia a responsabilidade do sistema municipal de educação para com a qualificação das professoras, bem como a necessidade de maior investimento na formação continuada e na construção de políticas públicas que assegurem condições adequadas para realização da formação e da valorização profissional. Nesse sentido, Kishimoto (1999, p. 75) assevera que, "pensar em uma política de formação profissional para educação infantil requer, antes de tudo, a garantia de um processo democrático que permita a ascensão na escolaridade, em todos os níveis, e a valorização dessa formação no patamar de outros cursos".

Concordamos com a autora, ao enfatizar a democracia e a valorização da formação como aspectos importantes na construção de uma política pública para formação de professores. Se na atualidade o contexto educativo requer uma formação que atenda às especificidades da criança, então, a política de formação profissional deve garantir a qualidade dessa formação dentro de um processo democrático visando a qualidade no seu atendimento.

Por fim, analisamos a questão em que as professoras emitiram "sugestões para melhorar a formação continuada da escola".Foi constatado que apenas uma profissional não se manifestou; desta forma, para procedermos à análise, as sugestões das professoras foram agrupadas em categorias, conforme veremos a seguir.

Na categoria Infraestrutura da escola constatamos aquilo que uma das professoras já havia pontuado: estrutura física precária tanto das salas de aula quanto do espaço para a formação e falta de material didático. Elas pontuam que um espaço adequado para a realização da formação, com equipamentos disponíveis, poderia melhorar a qualidade dos estudos realizados, bem como, obter melhor resultado na prática pedagógica. $\mathrm{O}$ atendimento deste desejo das professoras é o mínimo que se esperara do poder público como contribuição para a qualificação e a prática dos professores, com vistas à melhoria da qualidade do atendimento à criança, com bem ressalta Silva (2011, p. 204):

É bom lembrar, no entanto, que a qualidade do atendimento é resultado da interdependência entre diversos elementos que compõem a prática educativa, tais como as condições materiais, dentre elas o espaço físico, as condições de trabalho e sua possibilidades de organização, bem como o acesso a materiais que facilitem e/ou promovam uma interação enriquecedora para crianças e adultos nas instituições de educação infantil.

Como se pode observar, as instituições pesquisadas carecem de muitas melhorias para alcançar o objetivo da Educação Infantil, que é o desenvolvimento integral da criança, com vistas a fazer valer o que já foi conquistado nacionalmente: o direito da criança à educação de qualidade.

Na categoria Troca de experiências foi sugerido que a formação continuada deveria acontecer com tempo suficiente para que as professoras pudessem compartilhar seus anseios, dificuldades e avanços. Foi sugerido também que aconteçam oficinas para confecção de 
materiais pedagógicos, atividade esta que consideram importante para contribuir de maneira significativa para a melhoria da prática, uma vez que se beneficiarão com os materiais confeccionados. A proposição de oficinas pedagógicas é interessante, porém, deve acontecer articulada com a teoria, de forma que as professoras compreendam o objetivo de se utilizar determinados materiais para trabalhar com as crianças. Desta forma, os materiais confeccionados devem proporcionar uma prática mais atrativa e contribuir para desenvolver habilidades.

Nesta perspectiva, Bodnar (2011, p. 208) afirma que "a formação continuada é o lugar de compartilhar ideias, ouvir a voz do outro e a própria voz, ou seja, é um processo de troca que deveria fazer parte da ação cotidiana de todos os professores". Sendo assim, as respostas das professoras vêm ao encontro do que a autora expressa sobre como devem ser os encontros de formação. As professoras pesquisadas consideram importante o envolvimento de todos na elaboração da proposta de formação, posto que se trata de um momento no qual é possível definir temáticas e metodologias que direcionarão a formação continuada. Esse envolvimento culmina em proposições e tomadas de decisão acerca da vida da escola.

Por último, em relação à categoria Participação/envolvimento das professoras na formação, seis professoras afirmam que participam e contribuem para realização da formação continuada. Apenas uma professora, a mesma que praticamente em todas as questões demonstra insatisfação com a formação continuada, sugere que para planejar a formação deve-se saber primeiramente quais são as expectativas dos professores. Esta resposta chama atenção para um olhar mais atento por parte daqueles que são responsáveis pela formação continuada, tendo em vista a importância do envolvimento de todos nesse processo.

\section{Algumas considerações acerca dos resultados}

Nesta pesquisa o que se torna mais evidente é a participação das professoras na construção dos projetos de formação continuada da instituição em que atuam. Mesmo com o fato de uma professora não ter participado no primeiro momento de elaboração do projeto, não podemos dizer que não houve participação, já que essa situação foi revista pela gestão e a professora teve a oportunidade de participar da reelaboração do projeto, sugerindo temáticas a serem estudadas de acordo com suas necessidades.

Evidenciamos, de acordo com as respostas das professoras, que a grande maioria busca no cotidiano da Educação Infantil transpor para a prática os conhecimentos discutidos na formação continuada. Neste sentido, Oliveira (2011, p. 15) salienta que é no "âmbito do processo educativo que mais intimamente se afirma a relação entre a teoria e a prática. Essencialmente, a educação é uma prática, mas uma prática intencionada pela teoria”.

No que se refere à proposição de formação continuada, esta deve ser construída com base nas necessidades que o contexto educativo apresenta, considerando o envolvimento de todos e o tempo necessário para aprofundamento e assimilação do assunto em debate, de forma que venha contribuir na transformação dos fazeres pedagógicos.

As respostas das professoras revelam as precárias condições de infraestrutura para o desenvolvimento das práticas pedagógicas, bem como da realização da formação continuada. Desse modo, refletimos se o fato das escolas oferecerem, ou não, boas condições de trabalho é um fator predominante para a realização de práticas pedagógicas que não atendem as 
especificidades da criança, uma vez que, no momento da observação, constatamos práticas de qualidade dentro de um espaço com tão pouco a oferecer. Isso não significa que devemos aceitar as condições de trabalho encontradas nessas instituições, mas que precisamos buscar alternativas para superação das dificuldades encontradas tanto na formação continuada quanto na prática do profissional que atua na Educação Infantil, quiçá em qualquer nível de ensino.

Se considerarmos as respostas das professoras ao afirmarem que a formação oportuniza a participação ativa delas, que as temáticas desenvolvidas vão ao encontro de suas expectativas, que se sentem felizes ao atuarem na Educação Infantil e, ainda, se considerarmos a observação realizada in loco em que foram constatadas práticas que atendem as especificidades da faixa etária, podemos concluir que a formação, em alguns aspectos, tem contribuído com a prática docente.

É certo que algumas práticas positivas podem não ser reflexo direto da formação continuada, mas parece-nos que as professoras demonstram interesse em aprofundar seus conhecimentos sobre as temáticas estudadas na formação, o que nos leva a crer que mesmo implicitamente a formação continuada revela contribuições à prática das professoras.

De maneira geral, foi possível constatar que as professoras estão satisfeitas com a formação continuada desenvolvida em suas escolas, apresentando justificativas plausíveis de maneira a afirmar que participaram do processo de elaboração das propostas de formação e que esta tem contribuído com a sua prática pedagógica. Neste sentido, Oliveira (2010, p.15) enfatiza que a expectativa de mudanças na educação ocorre pelo "estimulante envolvimento dos educadores que atuam na área [...] e pela busca de formas de trabalho pedagógico que possam caminhar na direção pretendida”.

Sendo assim, o envolvimento das professoras nos projetos e nas propostas da instituição é fundamental para a proposição de ações que atendam a realidade do contexto educativo e, se isso vem ocorrendo na formação continuada das escolas pesquisadas, podemos concluir que este modelo de formação proporciona avanços que consideramos importantes para a melhoria da qualidade na Educação Infantil do município de Cáceres.

\section{Referências}

BARBOSA, M. C. As especificidades da ação pedagógica com os bebês. In: Orientações Curriculares Nacionais para Educação Infantil. Brasília: MEC/SEF, 2010.BODNAR, R. T. M. Relação teoria-prática na formação em serviço de profissionais da educação infantil: ressignificando a prática pedagógica. In: ROCHA, Eloisa A. C. KRAMER, Sonia. Educação Infantil: enfoques em diálogo. Campinas, SP: Papirus, 2011.

BRASIL. Senado Federal. Constituição da República Federativa do Brasil. 1988.

Ministério da Educação. Lei de Diretrizes e Bases da Educação Nacional. Lei Federal 9394 de dezembro de 1996.

GATTI, B.; BARRETO, E. S. S. Professores do Brasil: impasses e desafios. Brasília: UNESCO, 2009. 
GIL, A. C. Métodos e técnicas de pesquisa social. São Paulo: Atlas, 2009.

IMBERNÓN, F. Formação continuada de professores. Porto Alegre: Artmed, 2010.

KISHIMOTO, T M. Política de formação profissional para a educação infantil: Pedagogia e Normal Superior. Educação e Sociedade, v. 20, m. 68, Campinas, dez. 1999.

KRAMER, S. Profissionais de educação infantil: Gestão e formação. 1. ed. São Paulo: Bernardi, 2005.

OLIVEIRA-FORMOSINHO, J.; FORMOSINHO, J. A formação em contexto a perspectiva da associação criança. In: OLIVEIRA-FORMOSINHO, J. KISHIMOTO, T. M. (orgs.). Formação em Contexto: uma estratégia de integração. São Paulo: Pioneira Thomson Learning, 2002.

OLIVEIRA, Z. M. R. O currículo na educação infantil: o que propõem as novas diretrizes nacionais? Ministério da Educação. Orientações curriculares nacionais para educação infantil. Brasília: MEC/SEF, 2010.

Educação Infantil: fundamentos e métodos. 7 ed. São Paulo: Cortez, 2011.

SILVA, I. O. A profissionalização do professor de educação infantil: questões sobre formação dos profissionais que estão em serviço. In: Machado, M. L. de A. (org.). Encontros e Desencontros em Educação Infantil. 4. ed. São Paulo: Cortez, 2011.

Recebido em: 11/07/2014

Revisado em: 31/03/2015

Aprovado para publicação em: 20/04/2016

Publicado em: 30/04/2016 